\title{
CARNEIRO HIDRÁULICO COM TUBULAÇÃO DE ALIMENTAÇÃO EM AÇO GALVANIZADO E EM PVC
}

\author{
Caroline Abate ${ }^{1,3}$; Tarlei Arriel Botrel ${ }^{2 *}$ \\ ${ }^{1}$ Pós-Graduanda em Irrigação e Drenagem - USP/ESALQ. \\ ${ }_{3}^{2}$ Depto. de Engenharia Rural - USP/ESALQ, C.P. 9 - CEP: 13418-900 - Piracicaba, SP. \\ ${ }^{3}$ Bolsista CAPES. \\ *Autor correspondente<tabotrel@carpa.ciagri.usp.br>
}

\begin{abstract}
RESUMO: A recente crise da energia convencional tem ocasionado a exploração de fontes alternativas de energia. O bombeamento de água utilizando carneiro hidráulico é amplamente empregado em propriedades onde a energia elétrica é escassa ou inexistente. Procurando dar subsídios técnicos para a utilização do PVC nos sistemas de alimentação de um carneiro hidráulico, foi desenvolvido um experimento com objetivo de avaliar o desempenho de um carneiro hidráulico quando alimentado por uma tubulação de PVC e outra de aço galvanizado, sob três alturas de queda (2,1, 3,8 e 4,7 m). Foi utilizada a equação de D'Aubussion's para a avaliação do rendimento, calculado a partir de leituras de altura de recalque, vazão de escape, vazão de recalque e altura de alimentação. Pode-se conseguir o máximo rendimento com o carneiro hidráulico utilizandose de tubulação de PVC com até 4,2 m de desnível; além desse valor a tubulação de aço galvanizado é mais eficiente.
\end{abstract}

Palavras-chave: aríete hidráulico, golpe de aríete

\section{HYDRAULIC RAM PUMP PERFOMANCE WITH PVC AND STEEL PIPES}

\begin{abstract}
The recent conventional energy crisis is leading to the exploration of alternative energy sources. The pumping of water using ram pumps is widely used in farms where electric energy is scarce or inexistent. This experiment was carried out to evaluate the performance of an hydraulic ram pump utilizing two kinds of supply pipes (PVC and steel) using three different supply heads (2.1, 3.8 and 4.7). Delivery head, delivery discharge, waste discharge and supply head were utilized to calculate the yield of the hydraulic ram by the equation of D'Aubussion. The maximum yield of the hydraulic ram was obtained for the PVC pipe for the 4.2 $\mathrm{m}$ head; for heads higher than $4.2 \mathrm{~m}$ the steel pipe was more efficient.

Key words: ram pumps, water hammer
\end{abstract}

\section{INTRODUÇÃO}

A recente crise da energia convencional, tem ocasionado a exploração de fontes alternativas de energias para suprir usos doméstico, industrial e agrícola (Bhoi et al., 1994). O carneiro hidráulico ou aríete hidráulico é uma máquina simples que possui características geratriz e operatriz (Maclntyre, 1980). A fonte de energia é a altura de queda d'água que, em geral, é produzida artificialmente por meio de pequena barragem. O bombeamento de água utilizando carneiro hidráulico é amplamente empregado em muitas propriedades, principalmente onde a energia elétrica é escassa ou inexistente. Apresenta as vantagens de não necessitar de fonte externa de energia, manutenção barata e simples e não exigir mão-de-obra qualificada. $O$ funcionamento do carneiro hidráulico é decorrente do golpe de aríete causado pelo fechamento de uma válvula, que interrompe o movimento da água proveniente de uma fonte de alimentação localizada em nível superior. 0 fenômeno do golpe de aríete é de natureza complexa, cuja determinação é importante para a aplicação de medidas preventivas em situação onde este pode provocar avaria ao sistema de adução (Azevedo Netto, 1969).

Dentre as vantagens do carneiro hidráulico, citase: custo de aquisição baixo, pode ser instalado no tempo, sem necessitar de casa de bombas, não precisa de filtro, não utiliza energia externa para seu acionamento, pode ser utilizado $24 \mathrm{~h}$ por dia, bombeia sem emissão de poluentes ou gases (Horne \& Newman, 2000), a energia de alimentação é livre e renovável, não utiliza motor e custos de operação são baixos (BC Livestock Watering, 2000). Como desvantagens: eficiência é determinada pelas condições locais e golpe de aríete é barulhento.

O carneiro hidráulico é constituído por partes fixas e móveis. As partes fixas são: base, campânula e castelo. As partes móveis são: válvula de escape que é constituída de liga apropriada com longa duração e a válvula de recalque, revestida de couro ou de borracha. $\mathrm{Na}$ Figura 1 apresenta-se uma vista geral de um carneiro hidráulico desmontado. 
Na Figura 2 mostra-se um esquema funcional de um carneiro hidráulico de acordo com os princípios apresentados por Daker (1970):

Estando aberta a válvula $E$, a água conduzida de um ponto mais alto pelo tubo de alimentação $A B$, escapa por ela até que a pressão, em virtude da velocidade crescente do líquido, torna-se capaz de erguê-la, fechando-a bruscamente. A coluna de água desce pelo tubo $A B$ com velocidade progressiva, ficando num dado instante sem saída, produzindo o choque denominado "golpe de aríete", o qual abre a válvula de recalque $F$, permitindo a entrada da água na câmara de ar G. Como decorrência, o ar existente na parte superior da campânula é comprimido e oferece uma resistência crescente à entrada do líquido, chegando a tal ponto de fazê-la cessar, fechando-se, neste instante, a válvula F. Há produção de uma onda de pressão negativa em virtude do efeito da compressibilidade da água e da elasticidade da tubulação que atua na válvula $E$, fazendoa abrir novamente. Estando $\mathrm{E}$ aberta, há um novo ciclo e, com ciclos sucessivos, a água que vai penetrando na

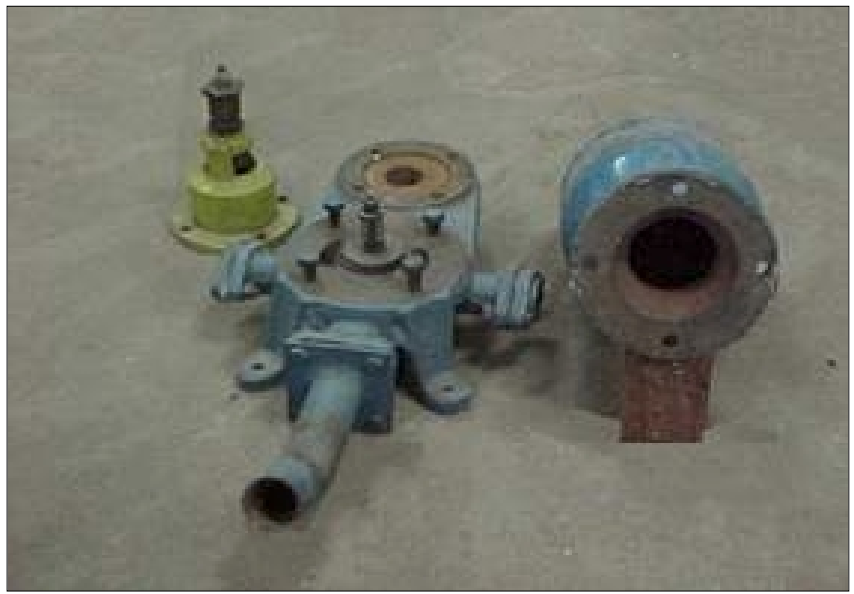

Figura 1 - Vista de um carneiro hidráulico desmontado.

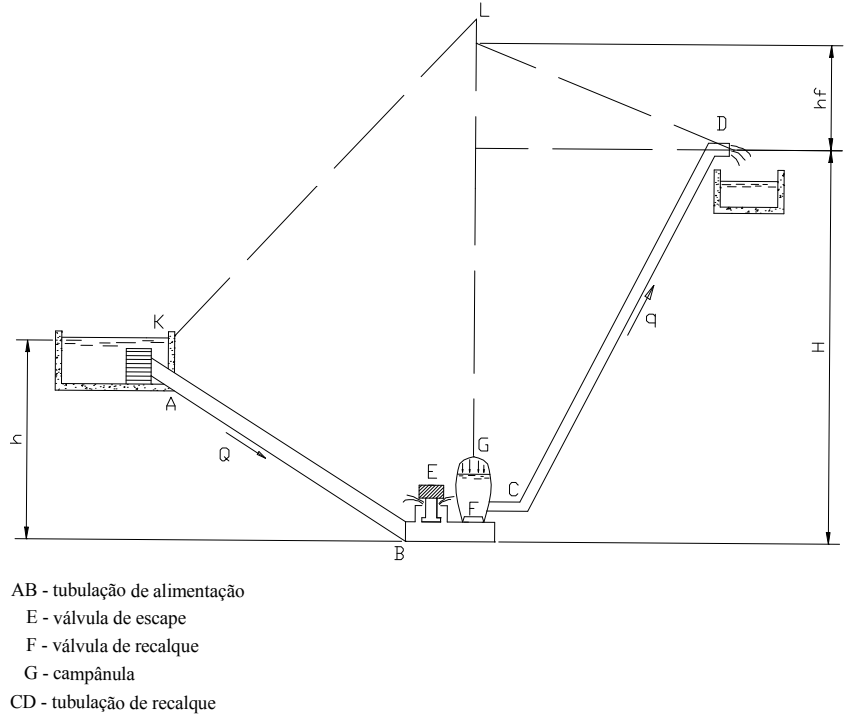

Figura 2 - Esquema funcional de um carneiro hidráulico. câmara de ar G, vai tendo pressão para subir no tubo de elevação $C D$, fazendo com que flua para o reservatório superior quando a pressão na campânula corresponder à altura manométrica de recalque.

O número de ciclos por minuto difere entre carneiros hidráulicos. Jennings (1996) descreve que o ciclo se repete entre 20 e 100 por minuto, dependendo da razão entre as vazões de alimentação e de recalque. Já Kitani \& Willardson (1984) descrevem que o ciclo se repete com uma freqüência de 30 a 100 por minuto, dependendo da construção do carneiro e dos ajustes.

São definidas como características operacionais de um carneiro hidráulico: altura de recalque, desnível entre o reservatório de alimentação e o carneiro hidráulico, comprimento das tubulações, diâmetro das tubulações, material constituinte da tubulação de alimentação, quantidade de água desperdiçada, vazão, batidas por minuto e rendimento.

A altura de elevação da água depende do carneiro hidráulico utilizado e das condições de instalação do mesmo. Corvalán \& Gálvez (2000) encontraram $300 \mathrm{~m}$ de altura de recalque para o carneiro hidráulico que tem $0,51 \mathrm{~m}$ de diâmetro na tubulação de alimentação e eleva cerca de $0,06 \mathrm{~m}^{3} \mathrm{~s}^{-1}$. Jennings (1996) encontrou $120 \mathrm{~m}$ de altura de recalque para um carneiro hidráulico com vazão de $3,15.10^{-3} \mathrm{~m}^{3} \mathrm{~s}^{-1}$; e BC Livestock Watering (2000) relacionou a altura de recalque (H) com a altura de alimentação (h):H = 6 a $12 \mathrm{~h}$.

Para o funcionamento de um carneiro hidráulico a fonte de energia é a potencial, a qual é convertida em energia cinética dentro da tubulação (Das et al., 1989). Há um limite tolerável de desnível geométrico entre o reservatório de alimentação e o carneiro hidráulico.

Bhoi et al. (1994) afirmam que o fator de grandeza é a razão entre altura de recalque $(\mathrm{H})$ e altura de alimentação (h), ou seja,

$$
\mathrm{f}=\frac{\mathrm{H}}{\mathrm{h}}
$$

Uma das características que mais divergem na literatura e entre os fabricantes é o limite de desnível mínimo e máximo entre o reservatório de alimentação e o carneiro hidráulico. Dentre os desníveis mínimos, foram encontrados de 0,45 m (Aqua Environment Co, 1997) a $2 \mathrm{~m}$ (Jeffery, 1992). Por exemplo: 0,5 m (Horne \& Newman, 2000; BC Livestock Watering, 2000; e Lifewater International, 2000), 0,6 m (Griffin, 2000), 1m (Thomas, 1994; Corvalán \& Gálvez, 2000; Jennings, 1996; Lifewater, 2000; e Roos et al., 2000). O máximo desnível encontrado foi de 7,5 m (Aqua Environment Co, 1997).

O comprimento da tubulação de alimentação recebe diferentes recomendações: 5 a 10 vezes a altura de alimentação (BC Livestock Watering, 2000); 8 até 12 vezes a altura de alimentação para desníveis maiores que $3 \mathrm{~m}$ e 5 até 8 vezes a altura de alimentação para desníveis entre 3 e 7,5 m (Aqua Environment Co, 1997); pelo menos 5 vezes a altura de alimentação (Jennings,

Scientia Agricola, v.59, n.1, p.197-203, jan./mar. 2002 
1996); 4 a 6 vezes a altura de alimentação (Lifewater International 2000); e 6 a 12 vezes a altura de alimentação (Kitani \& Willardson, 1984 e Krol, 1976).

Para um desempenho eficiente do carneiro hidráulico, Calvert, citado por Kitani \& Willardson (1984), indica que a razão entre o comprimento e o diâmetro da tubulação de alimentação deve ser de 150 até 1000.

Jennings (1996) afirma que o comprimento da tubulação de recalque geralmente é considerado de pouca importância para a instalação, pois a perda de carga por atrito é reduzida função da pequena vazão.

Corvalán \& Gálvez (2000) mencionam que o diâmetro da tubulação de alimentação varia entre 0,05 e 0,5 m, enquanto Horne \& Newman (2000) afirmam que o diâmetro da tubulação de alimentação varia de 0,025 a $0,1 \mathrm{~m}$ e o da tubulação de recalque varia entre $0,04 \mathrm{e}$ $0,05 \mathrm{~m}$, com 1 ou $2 \mathrm{~m}$ de desnível (Lifewater International 2000) recomenda que a tubulação de alimentação tenha no mínimo uma unidade de diâmetro maior que o da tubulação de recalque.

O material da tubulação de alimentação afeta o desempenho do carneiro. O módulo de elasticidade da tubulação causa significativas mudanças na elevação da pressão originada pelo golpe de aríete, decorrente da mudança de velocidade da onda de pressão na tubulação (Kitani \& Willardson,1984).

Lifewater International (2000) afirma que a tubulação de alimentação deve ser constituída de material pouco flexível para a máxima eficiência; geralmente utiliza-se tubulação de aço galvanizado, ao invés de plástico, devido ao efeito do golpe de aríete (BC Livestock Watering, 2000). Entretanto, Kitani \& Willardson (1984) recomendam o uso de PVC na tubulação de alimentação para recalque até $22,9 \mathrm{~m}$ ou 6 vezes menor ou igual a altura de alimentação.

Horne \& Newman (2000) afirmam que aproximadamente $3 / 4$ da água que passa através do sistema sai pela válvula de escape. Linsley (1992) observou que a razão entre a quantidade de água desperdiçada e bombeada é de 2:1 a 6:1.

Alguns valores de vazão para carneiros hidráulicos são apresentados por diversos autores e fabricantes: Jennings (1996) encontrou vazão máxima de recalque de $0,0032 \mathrm{~m}^{3} \mathrm{~s}^{-1}$ para um carneiro hidráulico que recalca $120 \mathrm{~m}$ de altura e possui tubulação de alimentação com 0,152 m de diâmetro; Corvalán \& Gálvez (2000) encontraram vazão de $0,06 \mathrm{~m}^{3} \mathrm{~s}^{-1}$ para um carneiro hidráulico com tubulação de alimentação de $0,51 \mathrm{~m}$ de diâmetro e com altura de recalque de $300 \mathrm{~m}$; Thomas (1994) e BC Livestock Watering (2000) afirmam que $10 \%$ da vazão de alimentação é recalcada, e Lifewater (2000) que, dependendo do desnível entre alturas de alimentação e recalque, poderá elevar-se de 1 - 20 \% da vazão de alimentação.

Refere-se "batidas", ao som emitido quando a válvula de escape se fecha, depois de completar um ciclo de operação (Bhoi et al., 1994). O número de batidas varia em função da condição de operação e regulagem feita na válvula de escape. A regulagem é feita aumentando ou diminuindo o curso da mesma, obtendose o máximo de rendimento do carneiro para cada condição de instalação.

Para menor número de batidas por minuto, desenvolve-se maior pressão, conseqüentemente recalca-se maior vazão por batida. É conveniente ensaiar, em cada instalação, vários números de batidas e selecionar aquela que proporciona o melhor rendimento ou a maior vazão de recalque.

Lal, citado por Das et al. (1989), demonstra três formas de calcular o rendimento de um carneiro hidráulico: Rendimento Volumétrico: razão da vazão recalcada e vazão total de água, Eq. (2); Rankine: razão entre o produto da vazão recalcada pela diferença de nível entre alimentação e recalque e pelo produto da vazão de alimentação e a altura correspondente, Eq. (3); D’Aubusisson: razão da vazão de recalque multiplicada pela altura de recalque e vazão total de alimentação multiplicada pela altura de alimentação, Eq. (4).

$$
\begin{aligned}
& \eta \%=\frac{q}{(Q+q)} \cdot 100 \\
& \eta \%=\frac{q \cdot(H-h)}{Q \cdot h} \cdot 100 \\
& \eta \%=\frac{q \cdot H}{(Q+q) \cdot h} \cdot 100
\end{aligned}
$$

sendo: $h \%$ - rendimento, \%; q - vazão recalcada, $\mathrm{m}^{3} \mathrm{~s}^{-1}$; $Q$ - vazão recolhida na válvula de escape, $\mathrm{m}^{3} \mathrm{~s}^{-1} ; \mathrm{h}$ altura de alimentação, $\mathrm{m} ; \mathrm{H}$ - altura recalcada, $\mathrm{m}$.

As equações de D'Aubusisson e Rankine são mais utilizadas; Kitani \& Willardson (1984) afirmam que a equação de Rankine apresenta valores ligeiramente menor que a equação de D'Aubusisson.

Diferentes valores de rendimentos foram encontrados na literatura: Maclntyre (1980) afirma que este valor está entre $50 \%$ e $80 \%$; Thomas (1994), entre 50 e $75 \%$; Jennings (1996), em torno de $60 \%$; e Slack et al., citado por Kitani \& Willardson (1984), destacam que para carneiros comerciais está em torno de $60 \%$ e para carneiros não-comerciais, de $80 \%$.

A capacidade ou tamanho do carneiro hidráulico refere-se à vazão de água de entrada, não levando em consideração o recalque; cada carneiro hidráulico necessita de uma vazão mínima e uma máxima para seu bom funcionamento (Zanini \& Beduschi, 1991). Fabricantes afirmam que vários fatores devem ser respondidos para a seleção do tamanho do carneiro hidráulico: vazão de alimentação, que deve ser verificada no período mais seco do ano; desnível entre o reservatório de alimentação e o 
carneiro hidráulico $(\mathrm{m})$; altura de recalque $(\mathrm{m})$; vazão de recalque $\left(\mathrm{m}^{3} \mathrm{~s}^{-1}\right)$ e comprimento da tubulação de recalque $(m)$.

Podem ser usados carneiros hidráulicos associados em paralelo quando a quantidade de água não for suficiente (Lifewater International, 2000).

Este trabalho teve como objetivo avaliar o desempenho de um carneiro hidráulico quando alimentado por tubulação constituída de PVC e de aço galvanizado sob carga variável.

\section{MATERIAL E MÉTODOS}

O experimento foi desenvolvido no Laboratório de Hidráulica do Departamento de Engenharia Rural da USP/ESALQ. Empregou-se um carneiro hidráulico Marumby número 4, com diâmetro de entrada de 0,038 m (1 1/2") e de saída de 0,019 m (3/4 ").

Como reservatório de alimentação, utilizou-se um tanque de $0,2 \mathrm{~m}^{3}$ com um dreno situado na metade da sua altura, fazendo com que o tanque permanecesse com $0,1 \mathrm{~m}^{3}$ de água em nível constante. Uma bomba centrífuga KSB, modelo ETA 50-26, vazão de $6,9 \times 10^{-3} \mathrm{~m}^{3} \mathrm{~s}^{-1}$; altura manométrica de $250 \mathrm{kPa}$; potência de $3,7 \mathrm{~kW}$ e $1710 \mathrm{rpm}$ foi utilizada para a alimentação desse tanque. Parte da água bombeada foi conduzida para a tubulação de alimentação e a água em excesso retornava através do dreno para o reservatório abastecedor. Parte da água que escoava através da tubulação de alimentação passava pelo carneiro hidráulico e era recalcada pelo carneiro hidráulico.

De acordo com as condições locais, foram adotados 3 desníveis entre o reservatório de alimentação e o carneiro hidráulico: $2,1 \mathrm{~m}, 3,8 \mathrm{~m}$ e $4,7 \mathrm{~m}$. Esses desníveis foram obtidos aumentando e abaixando o carneiro hidráulico e/ou o reservatório de alimentação, ficando o carneiro hidráulico bem fixado na base, afim de impedir que vibrações indesejáveis influíssem no rendimento.

Para se obter a posição 1 (desnível de 2,1 m), colocou-se o carneiro hidráulico na maior altura e o reservatório de alimentação na menor altura possíveis; para a posição 2 (desnível de $3,8 \mathrm{~m}$ ), tanto o reservatório como o carneiro hidráulico foram posicionados na maior

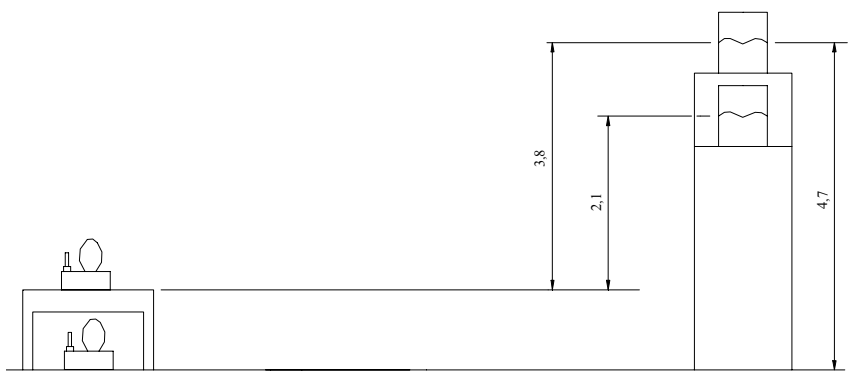

Figura 3 - Esquema dos diferentes desníveis de alimentação adotados. altura; e para a posição 3 (desnível de 4,7 m), colocouse o carneiro hidráulico na menor altura e o reservatório de alimentação na maior (Figura 3).

Foi utilizado o mesmo comprimento de tubulação de alimentação de $33 \mathrm{~m}$ para os dois materiais estudados. Quanto ao diâmetro interno da tubulação de alimentação, utilizou-se $0,038 \mathrm{~m}\left(1 \frac{1}{2}\right.$ ") para ambos materiais. Durante todo o ensaio, manteve-se a tubulação sempre retilínea e com declive.

Para cada teste de avaliação do desempenho do carneiro hidráulico, escorvou-se a tubulação de alimentação pressionando a válvula de escape e deixando a água extravasar. Após o escorvamento do sistema, abriu-se um pouco a válvula de recalque a fim de obter elevada pressão e pequena vazão.

O sistema ficou em funcionamento até a estabilização da leitura da altura de recalque e em seguida mediu-se as vazões de recalque e de escape, altura de recalque e batidas por minuto. Incrementou-se a vazão de recalque através do manuseio do registro de agulha na saída do tanque de estabilização.

Calculou-se o rendimento pelo método de D'Aubusisson para cada tipo de tubulação de alimentação e para cada desnível estudado. O cálculo do rendimento foi feito a partir das altura de recalque $(H)$, vazão de escape $(q)$, vazão de recalque $(Q)$ e altura de alimentação $(\mathrm{h})$.

Um manômetro digital Zurich com capacidade de 0-1000 kPa foi instalado junto ao tanque de estabilização, que estava ligado diretamente ao carneiro hidráulico, procurando melhorar a estabilização da leitura da altura manométrica de recalque.

A pressão gerada no interior do tanque de estabilização, quando transformada em altura de coluna de água corresponde exatamente à altura manométrica de recalque. $O$ controle da altura de recalque foi feito utilizando-se do registro de saída do tanque. Assim, menores aberturas do registro correspondem a maiores pressões.

Foram medidas diretamente as vazões de escape e de recalque. Para a vazão de escape, utilizouse de um balde de $0,02 \mathrm{~m}^{3}$ e mediu-se o tempo em que o volume foi preenchido. Para vazão de recalque, estipulou-se o tempo e pesou-se a quantidade de água no balde. Um registro de agulha inserido na saída do tanque de estabilização, permitiu a regulagem da vazão de recalque.

Com o auxílio de um cronômetro digital, foi determinado o número de batidas da válvula de escape no intervalo de um minuto.

Foi feita a análise de variância para a verificação da dependência dos dados, utilizando-se o teste $F$ aos níveis de $1 \%$ e $5 \%$ de probabilidade. $O$ valor de $R^{2}$ foi o parâmetro usado para verificar o ajuste das curvas de regressão dos dados observados. O rendimento em 
função da vazão de recalque foi ajustado por uma equação polinomial de segundo grau, e a pressão em função da vazão de recalque por uma equação exponencial.

\section{RESULTADOS E DISCUSSÃO}

Os dados foram analisados comparativamente considerando o desempenho do carneiro hidráulico quando alimentado pelas tubulações de aço galvanizado e de PVC. Na Figura 4 são apresentados os gráficos representativos da relação vazão vs pressão e do rendimento obtidos a partir dos dados do recalque e para cada desnível estudado.

$O$ rendimento diz respeito ao consumo de água para alimentar o carneiro hidráulico, ou seja, quanto menor a quantidade de água necessária ao acionamento, maior será o rendimento.

O rendimento em função da vazão foi ajustado ao modelo expresso pela Eq. (5), obtendo-se os parâmetros apresentados na Tabela 1.

$$
h=a \cdot q^{2}+b \cdot q+c
$$

sendo: h - rendimento, \%; a, b e c - parâmetros da equação, adimensional; $\mathrm{q}$ - vazão de recalque, $\mathrm{m}^{3} \mathrm{~s}^{-1}$.

Os valores de máximo rendimento foram obtidos a partir da raiz da derivada das equações de rendimento vs vazão, sendo que os resultados são mostrados na Tabela 2

Na situação de rendimento máximo, as vazões de recalque para a tubulação de alimentação de PVC foram maiores que as de aço galvanizado em todos os desníveis estudados. Quanto às pressões relacionadas ao rendimento máximo a tubulação de aço apresentou valores maiores que as da tubulação de PVC.

O máximo rendimento, de $78 \%$, ocorreu para a tubulação de aço galvanizado com o maior desnível $(4,7 \mathrm{~m})$; nas demais condições de desnível, a tubulação de PVC apresentou maior rendimento.

Quanto às pressões relacionadas ao máximo rendimento a tubulação de aço apresentou valores maiores que as da tubulação de PVC.

Pode-se inferir que existe um limite de desnível além do qual o máximo rendimento passa da tubulação
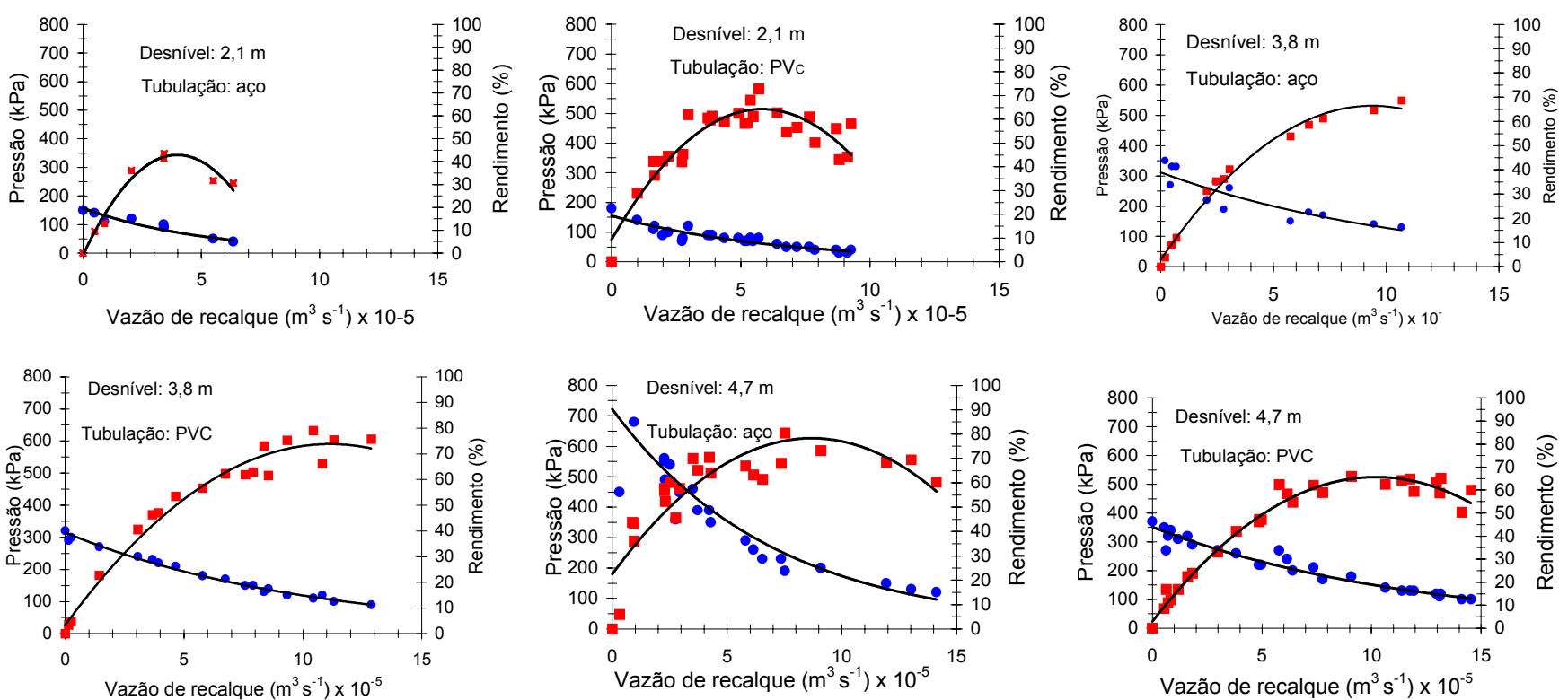

Figura 4 - Rendimento (ロ) e pressão (•) em função da vazão e do desnível da tubulação de alimentação e do material constituinte.

Tabela 1 - Parâmetros da equação rendimento vs vazão.

\begin{tabular}{lcccrl}
\hline Desnível & Material & Fator a & Fator b & Fator c & $\mathrm{R}^{2}$ \\
\hline $2,1 \mathrm{~m}$ & Aço & $-27504872273,7$ & 2191800,8646 & $-0,7252$ & $0,9661^{* *}$ \\
$2,1 \mathrm{~m}$ & PVC & $-16211700610,8$ & 1887114,3946 & 9,3550 & $0,8399^{\star *}$ \\
$3,8 \mathrm{~m}$ & Aço & $-7217079105,9$ & 1353889,7831 & 2,9810 & $0,9897^{\star *}$ \\
$3,8 \mathrm{~m}$ & PVC & $-5677894644,5$ & 1265100,5103 & 3,3570 & $0,9728^{\star *}$ \\
$4,7 \mathrm{~m}$ & Aço & $-7397692974,7$ & 1285544,3450 & 22,4730 & $0,7492^{* *}$ \\
$4,7 \mathrm{~m}$ & PVC & $-6039771607,5$ & 1231601,7883 & 2,9120 & $0,9787^{\star *}$ \\
\hline
\end{tabular}

${ }^{\star *}$ Valores significativos a $1 \%$. 
de PVC para a de aço galvanizado. A Figura 5 mostra o desnível de 4,2 m como este limite. Uma possível explicação é que comparativamente ao aço, a tubulação de PVC tem duas características distintas que irão influenciar no rendimento: uma favorável ao rendimento, é a menor rugosidade interna, conduzindo à menor perda de carga, a outra, desfavorável, é a maior elasticidade da tubulação, que absorve parte do golpe de aríete produzido. Em situações de menor altura de alimentação (menor que 4,2 m), portanto menor intensidade de golpe de aríete, o PVC provavelmente apresentou melhor rendimento que o aço galvanizado, isto porque o efeito favorável da rugosidade predominou sobre o efeito da maior elasticidade. Para as situações de maior golpe (maior que 4,2 m) a situação se inverteu, ou seja, predominou o efeito da menor elasticidade sobre a rugosidade, levando a resultados favoráveis o aço galvanizado, em termos de rendimento.

A pressão em função da vazão foi ajustada ao modelo expresso pela Eq. (6), obtendo-se os parâmetros apresentados na Tabela 3.

$$
P=f . e^{-k \cdot q}
$$

sendo: $\mathrm{P}$ - pressão, $\mathrm{kPa}$; $\mathrm{f}$ e $\mathrm{k}$ - parâmetros da equação, adimensional; $\mathrm{q}$ - vazão, $\mathrm{m}^{3} \mathrm{~s}^{-1}$.

Tabela 2 - Rendimento máximo, pressão e vazão de recalque correspondentes aos desníveis e materiais estudados

\begin{tabular}{lcccc}
\hline Desnível & Material & $\begin{array}{c}\text { Rendimento } \\
\text { máximo }\end{array}$ & Pressão & $\begin{array}{c}\text { Vazão de } \\
\text { recalque }\end{array}$ \\
\hline $2,1 \mathrm{~m}$ & Aço & 42,93 & 72,19 & $3,984387 \times 10^{-5}$ \\
\hline $2,1 \mathrm{~m}$ & PVC & 64,27 & 61,63 & $5,82022 \times 10^{-5}$ \\
$3,8 \mathrm{~m}$ & Aço & 66,47 & 135,48 & $9,37976 \times 10^{-5}$ \\
$3,8 \mathrm{~m}$ & PVC & 73,82 & 106,57 & $11,1406 \times 10^{-5}$ \\
$4,7 \mathrm{~m}$ & Aço & 78,32 & 209,71 & $8,68882 \times 10-5$ \\
$4,7 \mathrm{~m}$ & PVC & 65,69 & 148,89 & $10,1958 \times 10-5$ \\
\hline
\end{tabular}

Tabela 3 - Parâmetros da equação de regressão pressão vs. vazão.

\begin{tabular}{lcccc}
\hline Desnível & Material & Fator $\mathrm{f}$ & Fator $\mathrm{k}$ & $\mathrm{R}^{2}$ \\
\hline $2,1 \mathrm{~m}$ & Aço & 157,40 & 19561 & $0,9174^{* *}$ \\
$2,1 \mathrm{~m}$ & PVC & 155,38 & 15888 & $0,8901^{* *}$ \\
$3,8 \mathrm{~m}$ & Aço & 311,42 & 8872,9 & $0,8455^{* *}$ \\
$3,8 \mathrm{~m}$ & PVC & 315,07 & 9729,4 & $0,9881^{* *}$ \\
$4,7 \mathrm{~m}$ & Aço & 722,48 & 14236 & $0,8845^{* *}$ \\
$4,7 \mathrm{~m}$ & PVC & 350,56 & 8398,5 & $0,9634^{* *}$ \\
\hline
\end{tabular}

**Valores significativos ao nível de $1 \%$.
Tabela 4 - Pressão máxima para os desníveis e materiais estudados

\begin{tabular}{lcc}
\hline Desnível & Material & Pressão máxima \\
\hline $2,1 \mathrm{~m}$ & & $\mathrm{kPa}$ \\
$2,1 \mathrm{~m}$ & Aço & 157,40 \\
$3,8 \mathrm{~m}$ & PVC & 155,38 \\
$3,8 \mathrm{~m}$ & Aço & 311,42 \\
$4,7 \mathrm{~m}$ & PVC & 315,07 \\
$4,7 \mathrm{~m}$ & Aço & 722,48 \\
\hline
\end{tabular}

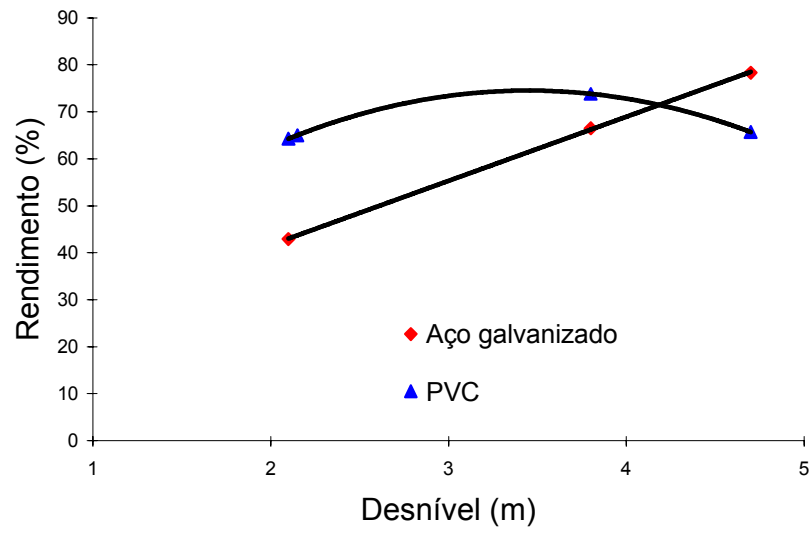

Figura 5 - Rendimento vs desnível estudado para os materiais.

A pressão máxima em foi obtida para vazão, a partir da equação correspondente a cada material e desnível estudado (Tabela 4).

Exceto para o desnível de $3,8 \mathrm{~m}$, a tubulação de aço galvanizado apresentou maior pressão máxima, apesar de da diferença entre pressões para o mesmo desnível serem pequenas, em torno de 4 $\mathrm{kPa}$. Para o máximo desnível $(4,7 \mathrm{~m})$, obteve-se grande diferença entre as pressões, em torno de 360 $\mathrm{kPa}$.

\section{REFERÊNCIAS BIBLIOGRÁFICAS}

AQUA ENVIRONMENT CO. Hydraulic water rams: catalogue. Bolina, 1997. 4p.

AZEVEDO NETTO, J.M. de Golpe de Ariete. In: ZAMBEL, A.R. Manual de aparelhos de bombeamento de água. São Carlos: USP/EESC, 1969. cap.10, p.183-209.

BC Livestock Watering. Hydraulic ram. http://www.bc.ducks.ca/ fs/watering/ hydraulic.htm. (29 Mar. 2000).

BHOI, K.L.; RAM S.; CHAUHAN. H.S. Field evaluation of hydraulic rams. ICID Bulletin, v.43, p.105-116, 1994.

CORVALÁN, A.; GÁLVEZ. R. Bomba de ariete hidráulico. http:/ /www.cipres.cec.uchile.cl/ rgalvez/bomba.htm. (29 Mar. 2000).

DAKER, A. A água na agricultura: captação, elevação e melhoramento da água. 3.ed. Rio de Janeiro: Freitas Bastos, 1970. v.2, 304p. 
DAS, K.C.; SHARMA, K.N.; PANIGRAHI, B.; SHARMA, S.D. Effect of magnification factor, supply conditions and valve clearence on performance of an hydraulic ram. In: INTERNATIONAL CONGRESS ON AGRICULTURAL ENGINEERING, 11., Dublin, 1989. Proceedings. Rotterdam: A.A. Balkema, 1989. p.721-725.

GRIFFIN, J. The motorless water pump. http://www.gravicheck.com/html. (29 Mar. 2000).

HORNE, B.; NEWMAN, C. Hydraulic ram. The Centre for Alternative Technology. http://www.cat.org.uk/information/ tipsheets/hydram.html. (29 Mar. 2000).

JEFFERY, T.D.; THOMAS, T.H.; SMITH, A.V.; GLOVER, P.B.; FOUNTAN, P.D. A guide to ram pump water supply systems. London: Intermediate Technology Publication, 1992. 135p.

JENNINGS, G.D. Hydraulic ram pumps. s.I: North Carolina Cooperative Extension Service, 1996. (EBAE 161-92).

KITANI, K.; WILLARDSON, L.S. Hydraulic ram use for sprinkle irrigation. Transaction of the ASAE, v.27, p.1788-1791, 1984.

KROL, J. The automatic hydraulic ram: its theory and design. New York: ASME, 1976. 12p. (Paper 76-DE-17).
LIFEWATER INTERNATIONAL. Designing a hydraulic ram pump. http://www.lifewater.org/wfw/rws4/rws4d5.htm. (29 Mar. 2000).

LIFEWATER. Hydraulic ram pumps. http://www.lifewater.ca/ ram/ram pump.htm. (29 Mar. 2000).

MACINTYRE, A.J. Bombas e instalações de bombeamento. 2.ed. Rio de Janeiro: Ed. Guanabara Dois, 1980.

ROOS, R.; ZWIENINK, S.; BATS, B. Ram pumps. http:// snt.student.utwente.nl/ wot/water/waterram.htm. (29 Mar. 2000).

THOMAS, T. Disseminating ram-pump technology. In: PICKFORD, J. (Ed.) Affordable water supply and santitation. Leicestershire: Loughborough University, 1994. Apresentado ao 20. WEDC Conference, Leicestershire, 1994 - Proceedings.

ZANINI, J.R.; BEDUSCHI, L.C. Elevação de água por aríete hidráulico e bomba de pistão acionada por roda d'água. Jaboticabal: UNESP/FCAV, Depto. de Engenharia Rural, 1991. 58p.

Recebido em 24.05.00 